\title{
Natural history for all Californians
}

\author{
The California Naturalist program, which links the state's residents with their natural surroundings, \\ is making strides toward addressing its diversity challenges.
}

California Conservation Corpsmembers support a nature discovery field trip at the Hopland Research and Extension Center.

$$
\mathrm{t}
$$

t was only in 2014 that UC California Naturalist became a UC Agriculture and Natural Resources (ANR) statewide program - but already the program has delivered its trademark 40-hour certification course to thousands of Californians. The program's instructors, in the classroom and in the field, have introduced students to the fundamentals of environmental science and to the wonders of California's habitats, natural history and more. The program exposes students to science-based content, teaches them practical skills and provides them opportunities for stewardship in areas such as habitat restoration, education and community and citizen science. The California Naturalist program, which fosters deep relationships with dozens of partner organizations, has established itself as an important resource for environmental education and stewardship training across broad swaths of the state.

All that said, the program has encountered - and is working to overcome - challenges in the realm of diversity and inclusiveness. The most common profile of an individual who earns California Naturalist certification is a white, college-educated woman over the age of 50. The California Naturalist program, because it aims to more closely reflect the state's diversity - and in particular to increase participation by young, Latino and African-American Californians - is pursuing several strategies to engage a broader audience, reduce barriers to participation in the program and increase the cultural relevance of the California Naturalist experience.

One approach is to partner with workforce development organizations such as conservation corps. Under this approach, California Naturalist partners with a workforce development organization to codesign a specialized version of the course that achieves greater relevance for participants. In Southern California, for example, California Naturalist has teamed up with the National Forest Foundation (NFF), three national forests, and several workforce development programs that serve diverse communities. The NFF, with the aid of workforce development organizations and the U.S. Forest Service, recruits young people into a youth engagement program called Junior Field Rangers. The NFF helps participants prepare for the program, notably by arranging for them to earn California Naturalist certification. Junior Field Rangers interact with the public at cooperating national forests, with duties including educating visitors about forest stewardship, water resources and sustainable recreation. Dania Gutierrez, the NFF's Southern California program manager, reports that as many as 300 students have participated in the Junior Field Rangers program since its inception.

\section{Online: https://doi.org/10.3733/ca.2020a0006}




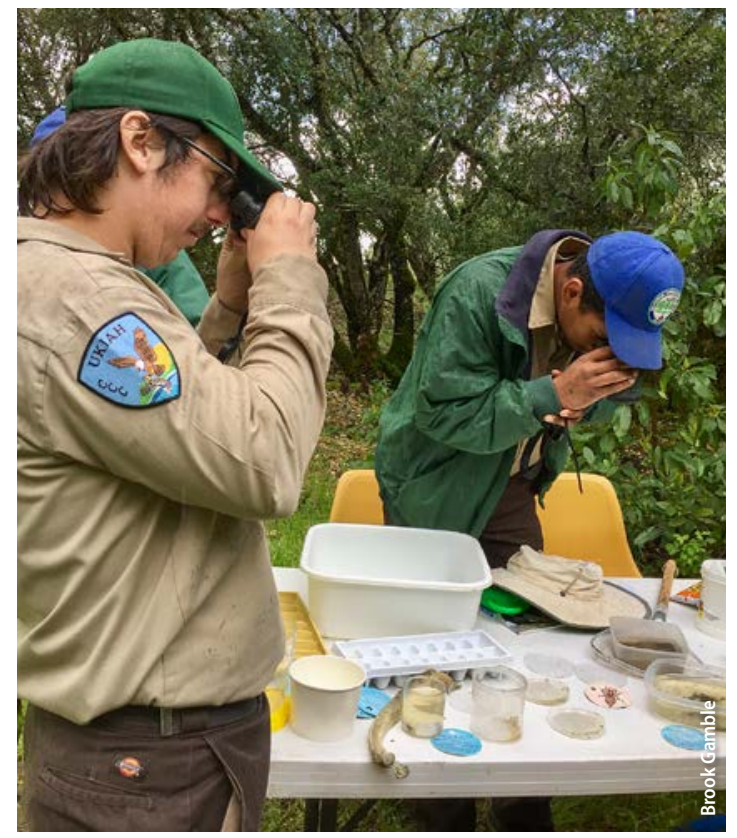

California Conservation Corpsmembers identify organisms collected during a bioblitz at the Hopland Research and Extension Center.

Elsewhere in the state, California Naturalist is strengthening its relationship with the California Conservation Corps (CCC), a state department whose dual missions are to restore and enhance California's natural resources and to foster the personal and professional development of "corpsmembers," who range in age from 18 to 25 . The corpsmembers, who spend a year engaged in "project work" such as trail repair and invasive species removal, very much reflect the diversity of the state, says Hunt Drouin, the CCC's program development manager.

California Naturalist and the CCC are now partnering to pilot a course in which corpsmembers earn California Naturalist certification as part of their service. In April, about 30 corpsmembers based at the CCC's residential center in Ukiah will travel daily to UC ANR's nearby Hopland Research and Extension Center for a specially designed immersion course. The curriculum, to accommodate corpsmembers' somewhat unpredictable schedules, will be compressed into one week (compared to the usual 10 or so). The course will help corpsmembers develop skills particularly relevant to their work and will provide them enhanced instruction in areas such as fire prevention. Representatives of three CCC residential programs elsewhere in the state will observe and assess the pilot course; according to California Naturalist Director Gregory Ira, the result could be broader adoption of the California Naturalist program across the CCC.

Funding for the pilot project is provided by a Renewable Resources Extension Act Capacity Grant. Additional funding comes from several private donors and from the CCC Foundation, which will cover fees for students who exercise the option,

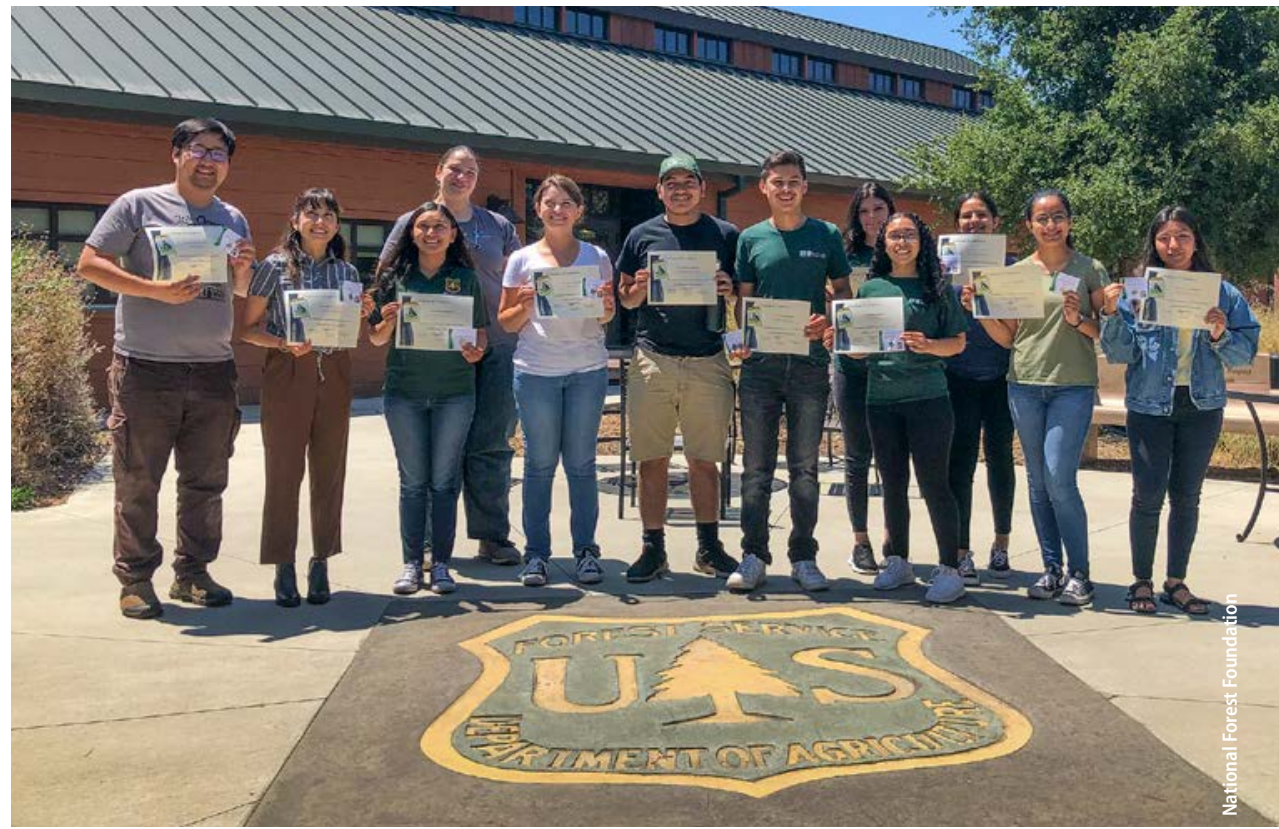

Students and instructor from the National Forest Foundation Angeles/San Gabriel Mountains course displaying their CalNat certificates.

available to anyone who earns California Naturalist certification, to receive four units of college credit from UC Davis Continuing and Professional Education. Under a separate arrangement, all corpsmembers became eligible last year to apply a portion of the educational scholarship they receive upon completion of their service to enrollment in a California Naturalist course.

Thanks in part to the collaborations discussed here, California Naturalist is making strides toward achieving its diversity, equity and inclusion objectives. Between 2015 and 2017, for example, Latino representation in California Naturalist courses increased to 9\% from 3\%. California Naturalist - by pursuing additional initiatives such as scholarship programs, equity pricing and collaborations with community colleges and tribes - is working to build a yet more inclusive community of naturalists around the state.

\section{- Editors}

An LA Conservation Corpsmember learns how to use a refractometer to determine salinity of a local waterbody during a California Naturalist course at the SEA Lab.

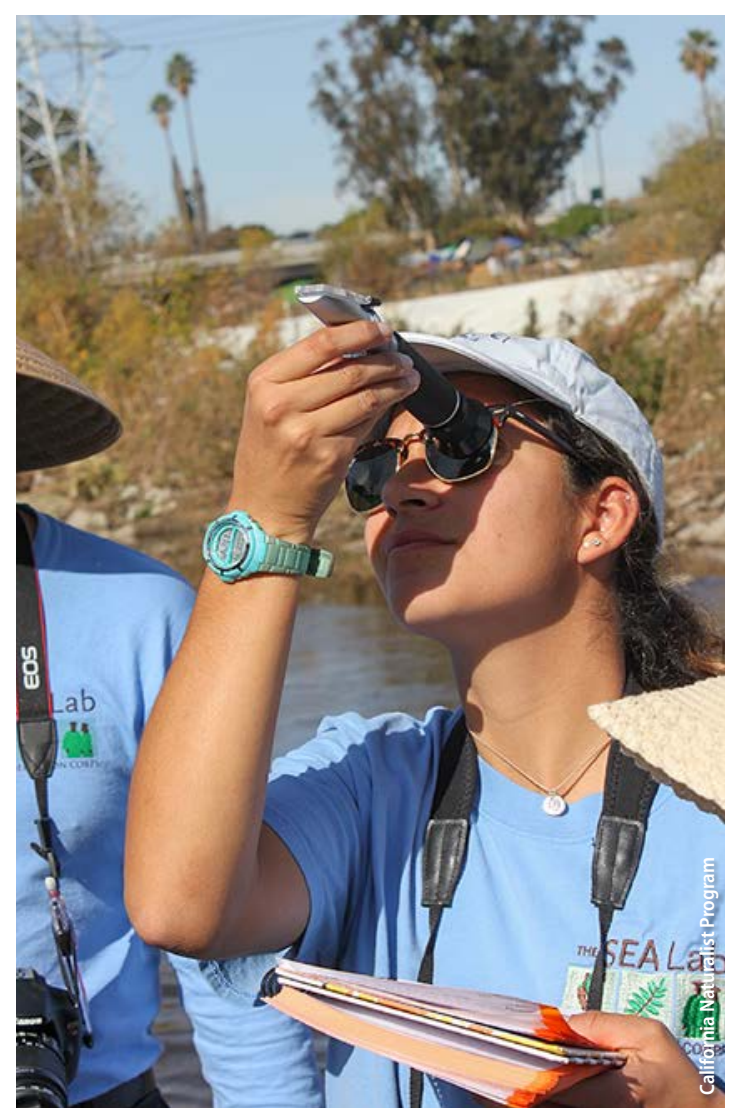

